TITLE:

\title{
Thioredoxin binding protein-2 mediates metabolic adaptation in response to lipopolysaccharide in vivo.
}

\section{AUTHOR(S):}

Oka, Shin-ichi; Liu, Wenrui; Yoshihara, Eiji; Ahsan, Md Kaimul; Ramos, Dorys Adriana Lopez; Son, Aoi; Okuyama, Hiroaki; ... Masutani, Hiroshi; Nakamura, Hajime; Yodoi, Junji

\section{CITATION:}

Oka, Shin-ichi ... [et al]. Thioredoxin binding protein-2 mediates metabolic adaptation in response to lipopolysaccharide in vivo.. Critical care medicine 2010, 38(12): 2345-2351

\section{ISSUE DATE:}

2010-12

\section{URL:}

http://hdl.handle.net/2433/156276

\section{RIGHT:}

(c) 2010 by the Society of Critical Care Medicine and Lippincott Williams \&Wilkins; この論文は出版社版でありません。引用の際には出版社版を ご確認ご利用ください。; This is not the published version. Please cite only the published version. 
Thioredoxin binding protein-2 mediates metabolic adaptation in response to lipopolysaccharide in vivo.

Shin-ichi Oka,PhD; Wenrui Liu, MD, PhD; Eiji Yoshihara MS; Md. Kaimul Ahsan, MD, PhD; Dorys Adriana Lopez Ramos, BS; Aoi Son DDS, PhD; Hiroaki Okuyama, MD, PhD; Li Zhang, MD; Hiroshi Masutani, MD, PhD; Hajime Nakamura, MD, PhD; and Junji Yodoi, MD, PhD

Laboratory of Infection and Prevention, Department of Biological Response, Institute for Virus Research, Kyoto University, 53 Shogoin, Kawahara-cho, Sakyo-ku (SO, WL, EY, DALR, AS, HM, JY), Department of Experimental Therapeutics, Translational Research Center, Kyoto University Hospital, 54 Shogoin, Kawahara-cho, Sakyo-ku (MKA, HO, HN, JY), Kyoto 606-8507, Japan, Division of Systemic Life Science, Graduate School of Biostudies, Kyoto University, Kyoto (EY, DALR), Japan., Department of Genetic Medicine and Ansary Stem Cell Institute, Weill Cornell Medical College, 1300 York Avenue, New York, NY 10065, USA (LZ).

SO and WL equally contributed to this study.

The authors have not discovered any potential conflicts of interest.

Supported, in part, by a New Energy and Industrial Technology Development Organization 
Fellowship Program (SO), Japan Society for the Promotion of Science (JSPS) with Postdoctoral Fellowships for Foreign Researchers (WL and MKA) and the Japan Society for the Promotion of Science (JSPS) with a Predoctoral Fellowship (EY).

This work was supported in part by the Program for the Promotion of Fundamental Studies in Health Sciences of the National Institute of Biomedical Innovation (NIBIO) (JY).

\section{Correspondence:}

\section{Junji Yodoi, MD, PhD}

Department of Biological Response, Institute for Virus Research, Kyoto University, 53 Shogoin, Kawahara-cho, Sakyo-ku, Kytoto 606-8507, Japan. Phone: 81-75-751-4024; Fax 81-75-761-5766; E-mail: yodoi@virus.kyoto-u.ac.jp

Key words: Thioredoxin binding protein-2 (TBP-2), endotoxicemia, fatty acid oxidation disorder, hyperinsulinemia, hyperlipidema, hypoglycemia

Present addresses: Department of Cell Biology and Molecular Medicine, Cardiovascular Research Institute, University of Medicine and Dentistry of New Jersey, New Jersey Medical School, 185 South Orange Avenue, Newark, NJ 07101 (SO), Department of Developmental Biology, Weill Cornell Medical College, 1300 York Avenue, New York City, NY 10021 (WL), Cardiovascular Research Center, Department of Surgery, School of Medicine, University of Connecticut Health Center, 263 Farmington Avenue, Farmington, CT 06030 (MKA), USA. Osaka Medical Center for Cancer and Cardiovascular Diseases, 
1-3-3 Nakamichi, Higashinari-ku, Osaka 537-8511 (HO), The Tazuke Kofukai Medical Research Institute, 2-4-20 Ohgimachi, Kita-ku, Osaka 530-8480(HN), Japan. 


\section{Abstract}

Objective: Endotoxin triggers a reorganization of the energy metabolic pathway, including the promotion of fatty acid utilization to adapt to a high energy demand during endotoxemia. However, the factors responsible for the metabolic adaptation and characteristic pathologies resulting from defective utilization fatty acids during endotoxin response have not been fully clarified. The thioredoxin binding protein-2 knockout $\left(\mathrm{TBP}-2^{--}\right)$mouse is an animal model of fatty acid oxidation disorder. The aim of this study was to determine whether and how TBP-2 is involved in metabolic regulation in a lipopolysaccharide (LPS)-induced endotoxemia model in mice.

Design: Prospective animal trial.

Setting: Research laboratory.

Subjects: TBP- $2^{-{ }_{-}^{-}}$and wild control mice.

Intervention: $\mathrm{TBP}_{-} 2^{-/-}$and wild control mice were intraperitoneally injected with LPS. Mortality, serum levels of markers of hepatorenal injuries, cytokines, insulin, glucose and lipid derivatives, and the hepatic signaling pathway regulating gluconeogenesis were investigated.

Measurements and main results: Following the administration of LPS, TBP- $2^{-/-}$mice showed a predisposition for death without any significant elevation of inflammatory cytokines, compared to the wild mice. LPS-challenged TBP- $2^{-/}$mice showed fat deposition in the liver and kidney, organ injuries, glycogen depletion, and elevation of serum lipid derivatives such as free fatty acids, triglyceride and cholesterol. Hyperinsulinemia and hypoglycemia were observed in TBP- $2^{-/-}$mice after LPS injection. Death due to the LPS 
administration was prevented by supplementation of glucose. Phosphorylation of Akt and FoxO1, an inhibitory pathway of gluconeogenesis in the liver of LPS-challenged TBP- $2^{-/-}$ mice was demonstrated, suggesting the enhancement of insulin signaling.

Conclusions: TBP-2 is involved in metabolic control during LPS-induced endotoxemia. After the LPS challenge, TBP- $2^{-/-}$mice showed several characteristic aspects, such as hepatorenal injuries, and dysregulation of the lipid and glucose metabolisms. Furthermore, hypoglycemia promoted by hyperinsulinemia may be a critical risk factor for mortality in circumstances where fatty acid utilization is impaired during endotoxemia. 


\section{Introduction}

Sepsis and septic shock that are characterized as widespread and systemic inflammatory reactions that can be triggered by an increase in the circulating levels of endotoxins, which are provoked by bacterial infection, representing a major cause of mortality in hospitalized patients[1,2]. Mitochondria fatty acid oxidation is considered to be important for energy homeostasis, especially under conditions requiring a high energy demand, such as fasting and infection[3]. Several reports have shown that endotoxins alter energy metabolism, including the augmentation of glucose and fatty acid utilization, most probably due to the high energy demand in endotoxemia and/or septic conditions[4-7]. However, excessive endotoxins impair the function of the mitochondria, which in turn results in impaired fatty acid utilization[8-10]. Several symptoms, such as multiple organ failure, hypoglycemia, hyperlipidemia, and liver steatosis are commonly observed in sepsis, endotoxemia and fatty acid oxidation disorders (FAODs), also known as the Reye-like syndrome, which is caused by both inheritable and heritable defects of mitochondria fatty acid oxidation[11-15]. In spite of those similar pathologies, as well as the existence of individuals with insufficient fatty acid oxidation, the molecular mechanism and consequence of insufficient fatty acid oxidation in endotoxemia remains to be elucidated.

TRX-binding protein-2 (TBP-2) was identified as a binding protein of Thioredoxin-1 (TRX) by yeast two-hybrid screening using TRX as bait[16]. TBP-2 binds to TRX through the formation of a mixed disulfide[17], which results in competitive inhibition of the other target molecules of TRX[16, 18]. Growing evidence has suggested that TBP-2 serves a wide range of biological functions, including tumor suppression, cellular development and 
metabolic control[19-21]. TBP-2 knockout $\left(\right.$ TBP- $\left.2^{-/-}\right)$mice have defective fatty acid utilization, thereby showing compatible phenotypes of human FAODs under fasting conditions[20, 22, 23]. We hypothesized that TBP-2 is involved in fatty acid oxidation in endotoxemia, and therefore, that TBP- $2^{-/-}$mice provide a suitable animal model to evaluate the sequential pathology resulting from the inability to utilize fatty acids during endotoxemia.

In the present study, we explored the role of TBP-2 in an animal model of endotoxemia using intraperitoneal injections of lipopolysaccharide (LPS), a cell wall component derived from gram-negative bacteria, to TBP- $2^{-/-}$mice. Our results demonstrated that $\mathrm{TBP}-2^{-/-}$mice showed a high mortality with pathologies partly similar to those shown in human septic patients, as well as FAODs, after LPS administration, suggesting that the inability to utilize fatty acid is a crucial risk factor for mortality in endotoxemia. 


\section{Materials and methods}

\section{Animals}

Thioredoxin binding protein-2-deficient $\left(\mathrm{TBP}-2^{-/-}\right)$mice were backcrossed for at least 5 generations to C57BL/6 backgrounds. All of the mice were housed in the specific pathogen-free animal facility at the Institute for Virus Research, Kyoto University. All of the procedures involving animals were performed in accordance with the protocols approved by the Kyoto University Institutional Animal Care and Use Committee.

\section{Western blot analysis}

The liver was dissected and lysed with lysis buffer containing $1 \%$ NP40, $1 \%$ Na-deoxydulate, 0.1\% SDS, $20 \mathrm{mM}$ Tris (pH7.5), $5 \mathrm{mM}$ EDTA, $150 \mathrm{mM} \mathrm{NaCl}$, protease inhibitors (Complete, Roche) and phosphatase inhibitors (PhosStop, Roche). Western blot analysis was performed using an ECL Western blotting detection system (Amersham Biosciences), according to the manufacturer's instructions. Anti-Akt, anti-phosphorylated specific Akt (Ser473), anti-FoxO1 and anti-phosphorylated specific FoxO1 (Ser256) were purchased from Cell Signaling.

\section{Induction of endotoxemia}

LPS from Escherichia coli (055:B5, Sigma, St. Louis, MO) was intraperitoneally injected (i.p.) with 1,5 or $25 \mathrm{mg} / \mathrm{kg}$ of body weight in $200 \mu \mathrm{l}$ of saline. Unless indicated otherwise, one $\mathrm{mg} / \mathrm{kg}$ of body weight LPS was injected. Animals of sham control groups were administered i.p. with $200 \mu \mathrm{L}$ of saline only. Mortality was recorded every 8 hours 
and continued up to 120 hours after LPS injection.

\section{Histopathology}

Under anesthesia, the liver and kidney were removed at appropriate time points, fixed in $10 \%$ buffered formalin, and embedded in paraffin, followed by staining with hematoxylin and eosin (H \& E), periodic acid-schiff(PAS) and anti-NIMP-R14 antibody (Abcam).

\section{Blood Biochemical Examine}

Mice were injected with LPS in saline or saline alone, as mentioned above. Blood was collected from the retro-orbital, and clarified sera samples were stored at $-20^{\circ} \mathrm{C}$ for the biochemical examinations.

\section{ELISA Analysis}

Mice were injected with LPS in saline or saline alone, as mentioned above. Blood was collected from the retro-orbital at the indicated times, and clarified sera samples were stored at $-80^{\circ} \mathrm{C}$. Serum interferon- $\gamma(\mathrm{IFN}-\gamma)$, INF- $\beta$, tumor necrosis factor- $\alpha$ (TNF- $\alpha$ ), interleukin-6 (IL-6), and IL-10, monocyte chemoattractant protein-1 (MCP-1), macrophage inflammatory protein-2 (MIP-2) levels were determined using ELISA Development Systems (R \& D Systems, Inc., Minneapolis, MN).

\section{Semiquantitative and quantitative RT-PCR analysis}


Following LPS injection, the liver was removed, and the total RNA was extracted using TRIzol reagent (Life Technologies, Inc), according to the manufacturer's instructions. Reverse transcription was performed with a SuperScript III First-Strand Synthesis System kit (Invitrogen). Real-time RT-PCR was performed using SYBR Premix Ex Tag (TAKARA). PCRs were carried out using the following primers:

TBP-2 sense (5'-GTGATGGATCTAGTGGATGTC-3'), antisense (5'-TCACTGCACGTTGTTGTTG-3'), $\beta$-actin sense (5'-ATGGATGACGATATCGCTGCGCT-3', and antisense (5'-TAGAAGCACTTGCGGTGCACGAT-3'). Amplification of the products was not saturated with the number of cycles we performed.

\section{Statistics Analysis}

Results were expressed as mean \pm SD. Statistical comparisons were performed by 1-way ANOVA, followed by Student-Newman-Keul's post-hoc analysis. Survival data were evaluated using the kaplan-meier log-rank test. Findings of $\mathrm{P}<0.05$ were considered as statistically significant and shown by an asterisk. 


\section{Results}

\section{$T B P-2^{-/-}$mice are susceptible to LPS-induced endotoxemia.}

In order to investigate the role of TBP-2 in response to LPS, wild, TBP-2 heterozygous knockout $\left(\mathrm{TBP}^{\left.-2^{+-}\right)}\right.$and homozygous knockout $\left(\mathrm{TBP}-2^{-/}\right)$mice were injected intraperitoneally (i.p.) with doses of 1,5 , or $25 \mathrm{mg} / \mathrm{kg}$ of body weight of LPS. As shown in Fig. $1 \mathrm{~A}$, both male and female TBP- $2^{--}$mice showed a significant susceptibility to LPS, compared with the wild mice in all of the doses we tested. Before death, these mice showed severe debility and hypothermia (data not shown). This susceptibility was also observed in ICR and Balb/c genetic background TBP- $2^{-/}$mice, suggesting that the high susceptibility to LPS does not depend on the genetic background of mice (Supplementary Fig. 1A). TBP-2 ${ }^{+/}$ mice showed a tendency for a high mortality, compared to wild mice after LPS administration. RT-PCR examination revealed that TBP-2 expression was up-regulated in the liver after 1 hour after the LPS administration and the expression was sustained for 24 hours (Fig. 1B). LPS-induced TBP-2 expression was attenuated in TBP- $2^{+/-}$mice, compared to wild mice, suggesting that up-regulated TBP-2 may partly contribute to animal survival in the response to LPS (Fig. 1C). These results suggested that TBP-2 is an endotoxin response gene and plays an important role in animal survival in LPS-induced endotoxemia.

\section{Hypercytokinemia is not observed in LPS-challenged TBP-2 $2^{-/}$mice.}

Since hypercytokinemia has been associated with high mortality in several animal models showing a high susceptibility to LPS, we then investigated whether or not there were any differences between wild and TBP- $2^{-/-}$mice in the LPS-induced production of 
inflammatory cytokines. The serum levels of TNF $\alpha$, IL-6, IL-10, INF $\beta$, INF $\gamma$, MCP1 and MIP2 were measured after LPS injection. As shown in Fig. 2A, TBP-2 $2^{-/-}$mice did not show higher levels of those cytokines compared to wild mice, but rather slightly lower levels of INF- $\beta$ and MCP-1 at particular time points. As consistent with cytokine and chemokine levels, neutrophil infiltrations were not significantly changed between the wild and TBP- $2^{-/-}$ mice (Figure 2B). These results suggested that the high susceptibility of TBP-2 $2^{-/}$mice was not associated with the enhancement of cytokine production.

\section{Fat accumulation in TBP-2-/ mice following LPS injection}

Histological studies were performed in order to investigate the abnormality of TBP- $2^{-/-}$ mice. Hematoxylin and eosin staining revealed that microvesicular and macrovesicular steatosis occurred in the liver and kidney of $\mathrm{TBP}-2^{-/-}$mice, but not in the wild mice after LPS administration. Mild hepatic steatosis was also observed in TBP- $2^{+/-}$mice after LPS administration (Supplementary Fig. 2). In addition, the glomerular structure was destroyed in the kidney of LPS-injected TBP-2/- mice (Fig. 3A).

Several serum makers were examined in order to investigate those organ injuries. As shown in Fig. 3B, the levels of alanine aminotransferase (ALT), aspartate aminotransferase (AST), lacate dehydrogenase (LDH), blood urea nitrogen (BUN) and creatinene were elevated in $\mathrm{TBP}-2^{-/-}$mice by LPS-injection, compared to wild mice, indicating liver and renal injuries. Endotoxin-induced organs ischemia occasionally accompanies organ injuries, but we could not find any ischemic necrosis in the livers and kidneys or reduced liver weight, an index of reduced liver blood flow in TBP-2 $2^{-/-}$mice (Supplementary Fig. 3). 
These results suggested that LPS causes fat accumulation as well as those organ injuries in TBP- $2^{-/-}$mice.

\section{Plasma lipid derivatives are accumulated in TBP-2 $2^{-/}$mice following LPS injection}

Since steatosis was found in the liver and kidney of $\mathrm{TBP}-2^{-/-}$mice, we conducted examinations to determine if the lipid metabolism was dysregulated in those mice. As shown in Fig. 4, the plasma levels of free fatty acids, triglyceride, total cholesterol and phospholipids were increased in TBP- $2^{-/-}$mice, but not in wild mice, after LPS injection. LPS-induced hyperlipidemic features were also observed in C57B/6 F12 genetic background of TBP- $2^{-/-}$mice (Supplementary Fig. 1B). We have previously shown that these hyperlipidemic features were observed in $\mathrm{TBP}-2^{-/-}$mice during a fasting state[20]. Interestingly, the increased levels of the lipid derivatives were significant in the LPS injection mice, rather than with fasting. In addition, TBP- $2^{-/-}$mice showed a resistance against LPS-induced anorexia (Fig. 4B), indicating that the dyslipidemia is not simply due to LPS-induced anorexia in TBP- $2^{-/-}$mice. Thus, TBP-2 has an essential role in lipid homeostasis during LPS response. Notably, TBP- $2^{-/-}$mice show an insufficient fatty acid utilization[20], and therefore, accumulated free fatty acids were observed in those mice without LPS injection or fasting.

\section{Dysregulation of glucose metabolism triggers the fatality of LPS-injected TBP-2 ${ }^{-/}$mice.}

Hypoglycemia is occasionally observed in endotoxemia. To investigate whether TBP- $2^{-/-}$mice have abnormalities in the glucose metabolism during LPS response, the 
serum levels of glucose and insulin were examined. Plasma glucose levels were reduced at 24 hours after LPS injection in wild mice, while TBP- $2^{-/-}$mice showed more severe hypoglycemia (Fig. 5A). Plasma levels of insulin were significantly up-regulated in the TBP- $2^{-/}$mice (Fig. 5B). PAS staining revealed that glycogen was depleted in the liver of TBP- $2^{-/-}$mice after LPS injection, compared to wild mice (Fig. 5C), suggesting that accelerated glucose consumption due to hyperinsulinemia with insufficient fatty acid utilization is the more dominant constraint, compared to insulin-mediated inhibition of glycogen catabolism.

To investigate the role of hypoglycemia in the observable mortality, we examined whether glucose supplementation reduces the lethality induced by LPS in TBP- $2^{-/-}$mice. As shown in Fig 5D, lethality was not reduced in LPS-challenged TBP-2 ${ }^{-/-}$mice when these mice were housed with $20 \%$ glucose available in drinking water. In contrast, lethality was reduced in these mice by an intraperitoneal injection of glucose. Thus, forced glucose supplementation reduces the LPS-induced lethality in TBP- $2^{-/-}$mice. Taken together, this data indicates that LPS-induced hypoglycemia is a major cause of death in TBP- $2^{-/-}$mice.

\section{Insulin signaling is activated after LPS-challenge in TBP-2 $2^{--}$mice.}

Insulin promotes hypoglycemia through the induction of glucose uptake and the inhibition of gluconeogensis, which are mediated by Akt kinase. To investigate whether LPS-induced hyperinsulinemia activates Akt kinase, the phosphorylation levels of Akt were examined. As shown in Fig. 6A, LPS challenge significantly induced Akt phoshorylation in TBP- $2^{-/-}$mice, compared to the wild mice. Akt phosphorylates and inhibits FoxO1, a crucial 
transcription factor promoting gluconeogenesis[24]. As is consistent with the activation of Akt, phosphorylation levels of FoxO1 were up-regulated in $\mathrm{TBP}-2^{-/-}$mice after LPS injection (Fig. 6B). These results suggested that LPS-induced hyperinsulinemia activates insulin signaling to enhance hypoglycemia in TBP- $2^{-/-}$mice during LPS response.

\section{Discussion}

In our present study, we reported that $\mathrm{TBP}-2^{-/-}$mice showed a high susceptibility to LPS-induced lethality. Since the TBP- $2^{-/-}$mouse is an animal FAODs model[20], our data strongly suggested that insufficient fatty acid utilization is a risk factor for mortality during endotoxemia. TBP- $2^{-/-}$mice showed pathological features after LPS administration, such as fat infiltration into the liver and kidneys, multiple organ injuries, elevations of plasma lipid derivatives, hyperinsulinemia and hypoglycemia, which are most certainly enhanced by the inability for fatty acid utilization, resulting from the loss of TBP-2. Indeed, several characteristic features have also been reported in human patients developing sepsis as well as FAODs[12, 25, 26]. Recently, it was reported that dysregulations of mitochondria protein synthesis and gene expression were often observed in septic patients treated in an intensive care unit[27]. Taken together, those mitochondria dysfunctions might be not only the resultant pathology, but also a deterioration factor in endotoxemia.

The LPS-induced pathology of TBP- $2^{-/-}$mice were quite similar to fasting mice, such as multiple organ injuries, liver and renal steatosis (Fig. 3A and Supplementary Fig. 4), high levels of plasma lipid derivatives (Fig. 4A), hyperinsulinemia and hypoglycemia [20, 28]. Glucose supplementation also rescues fasting-induced abnormalities in TBP- $2^{-/-}$mice such 
as mortality and increased plasma revels of AST, ALT and creatinine[20]. Even though the triggering factor is different between fasting and LPS administration, most of the abnormalities seen seem to be similar. As is the case with $\mathrm{TBP}-2^{-/-}$mice, it has been reported that hyperinsulinemia associates with hypoglycemia in patients with Reye-like syndrome harboring mutation in medium- and short-chain 1-3-hydroxy-acyl-CoA dehydrogenase (M/SCHAD)[29]. It is likely that inability of fatty acid utilization augments glucose consumption to adapt high energy demand, which is enhanced by insulin. Although insulin is supposed to inhibit glycogen catabolism, glycogen was significantly depleted but that is not enough to normalize hypoglycemia in TBP- $2^{-/-}$mice. These results suggested that glucose is predominantly utilized during endotoxemia in circumstance where fatty acid is not available as an energy source due to impaired fatty acid catabolism. Even though it is currently unknown if hyperinsulinemia is associated with hypoglycemima or exacerbates abnormalities in endotoxemia, our data strongly suggested that hyperinsulinemia resulting in hypoglycemia is a critical risk factor in patients having insufficient fatty acid utilization.

In conclusion, this study suggests that mitochondria function inability is a risk factor for mortality in endotoxemia, and that the resultant pathological features are multi-organ injury, hypoglycemia and dyslipidemia without significant changes in cytokine levels. Since mitochondria function is disturbed by inborn defects as well as by an infection itself, these findings may be a good clue to develop novel therapeutic treatment for improving mortality in human patients. Although it remains unclear whether TBP-2 has a role in endotoxin-induced fatal syndrome following an infection in humans, our present study provides some intriguing implications and the possibility that TBP-2 is involved in such 
biological responses. Hence, TBP-2 may be a novel target molecule for therapeutic approaches for use in human diseases.

\section{Acknowledgments}

We would like to offer our thanks to Dr. Bin Tian at the University of Medicine and

Dentistry of New Jersey for his statistical review and to Ms. Ryoko Ohtsuki and Mr. Makoto Takenaka for their technical assistance. 


\section{Figure legends}

Figure 1. (A) Survival rates of TBP $-2^{-/-}$mice following LPS injection. TBP- $2^{-/-}, \mathrm{TBP}-2^{+/-}$ and wild mice were injected with the indicated dose of LPS. The number of mice examined was 8-12 (Male, $1 \mathrm{mg} / \mathrm{kg}$ ), 8-11 (Female, $1 \mathrm{mg} / \mathrm{kg}$ ), 8-9 (Male, $5 \mathrm{mg} / \mathrm{kg}$ ), 8 (Female, 5 $\mathrm{mg} / \mathrm{kg}$ ), 10-11 (Male, $25 \mathrm{mg} / \mathrm{kg}$ ) and 8 (Female, $25 \mathrm{mg} / \mathrm{kg}$ ) in each experimental group. (B-C) TBP-2 expression in the liver of wild and TBP-2 ${ }^{-/}$mice following LPS administration. Indicated time points (B) and 24 hours (C) after LPS injection. TBP-2 expression levels in the liver were analyzed with RT-PCR.

Figure 2. (A) Cytokine expressions in TBP-2 $2^{-/-}$mice following LPS administration. TBP-2 $2^{-/-}$ and wild mice were sacrificed at appropriate time points after LPS injection, respectively. Serum levels of indicated cytokines were analyzed. The number of mice examined was 3-8 (TNF- $\alpha$ ), 3-7 (IL-10), 3-7 (IL-6), 3-8 (IFN- $\gamma$ ), 3-5 (IFN- $\beta$ ), 4-5 (MCP-1) and 3-5 (MIP-2) in each experimental group. (B) Neutrophil infiltration in TBP- $2^{-/-}$mice following LPS administration. Anti-NIMP-R14 immunostaining were performed to examine neutrophil infiltration into the liver. The NIMP-R14 positive cells were stained as brown.

Figure 3. (A) Representative histopathology of the liver and the kidneys of TBP-2 ${ }^{-/-}$mice following LPS administration. H \& E staining was performed with dissected livers and kidneys at indicated time points after LPS administration. (B) Serum biochemical examination for the hepatocyte and renal cells injuries in TBP- $2^{-/-}$mice following LPS administration. Serum levels of AST, ALT, LDH, BUN and creatinine were examined at the 
indicated time points after LPS administration. The number of mice examined was 3-9 (AST), 4-9 (ALT), 3-9 (LDH), 3-9 (BUN) and 4-9 (Creatinine) in each experimental group.

Figure 4. (A) Serum biochemical examination for lipid metabolism in TBP-2 ${ }^{-/}$mice following LPS administration or fasting. Serum levels of free fatty acid, triglyceride, total cholesterol, and phospholipid were examined at the indicated time points after LPS administration or fasting. The number of mice examined was 3-10 (Free fatty acids), 3-14 (Triglyceride), 3-10 (Total cholesterol) and 3-10 (phospholipid) in each experimental group. (B) Amount of Food intake of TBP $-2^{-/-}$mice following LPS administration. TBP- $2^{-/-}$and wild mice were injected with LPS. The amount of food intake per 24 hours was examined at the indicated time points. At least 3 mice that survived at the indicated time points were examined for each experimental group.

Figure 5. The glucose metabolism of TBP- $2^{-/-}$mice following LPS administration. Serum levels of glucose (A) and insulin (B) were examined at the indicated time points following LPS administration. The number of mice examined was 3-5 (A) and 4-13 (B) in each experimental group. (C) TBP- $2^{-/-}$mice were treated with free drinking of $20 \%$ glucose(solid line), or injected with $4 \mathrm{~g} / \mathrm{kg}$ of body weight of glucose in distilled water (broken line) 24 hours following LPS administration. The survival rate of the animals was observed during the following 96 hours. The number of mice examined was 3 (free drinking), 9 (injection) in each experimental group. 
Figure 6. LPS activates insulin signaling in TBP- $2^{-/-}$mice. Phosphorylation levels of Akt (A) and FoxO (B) were examined by western blot analyses 24 hours after LPS administration. Coomassie brilliant blue (CBB) staining indicated that an equal amount of proteins were applied. The signal intensities were measured by the ImageJ program. Phosphorylated protein signals were individually divided by total protein signals. The signal intensities of the phosphorylated forms are shown relative to the control value (wild mice with saline treatment), which was taken as 1 . The results are shown as the mean \pm S.D. of 3 to 6 samples. (lower panels).

Supplementary Figure 1. (A) Survival rates of TBP-2 $2^{-/-}$of ICR and Balb/c genetic background mice following lipopolysaccharides (LPS) injection. The survival rates of these mice were observed for 96 hours following LPS administration. At least 4 mice were examined for each experimental group. (B) LPS induces organ injuries and metabolic dysregulation in C57B/6 F12 background TBP-2 $2^{-/-}$mice. Indicated serum makers and metabolites were examined in TBP-2 $2^{-/}$of C57B/6 F12 background mice 24 hours after LPS administration. The number of mice examined was 3-5 (wild mice) and 3 (TBP-2 ${ }^{-/-}$mice) in each experimental group.

Supplementary Figure 2. LPS induces mild hepatic steatosis in TBP- $2^{+/-}$mice. H \& E staining was performed in the liver 24 hours after LPS administration. Sections from individual mice were shown. 
Supplementary Figure 3. Liver weight was not changed in $\mathrm{TBP}-2^{-/-}$mice. Liver weight/body weight ratio was evaluated 24 hours after LPS administration.

Supplementary Figure 4. Representative histopathology of the liver and the kidneys of TBP- $2^{-/}$mice following fasting and LPS administration. H \& E staining was performed using liver and kidneys at 24 hours after food deprivation or LPS injection. In addition to microvesicular and macrovesicular steatosis features after fasting and LPS administration, neutral lipid accumulation was assessed by Oil Red $\mathrm{O}$ staining in free feeding and fasting states of TBP-2 $2^{-/-}$mice (right lower corner). 


\section{References}

1. Angus DC, Linde-Zwirble WT, Lidicker J, Clermont G, Carcillo J, Pinsky MR: Epidemiology of severe sepsis in the United States: analysis of incidence, outcome, and associated costs of care. Crit Care Med 2001; 29:1303-1310.

2. Parrillo JE: Septic shock--vasopressin, norepinephrine, and urgency. $N$ Engl J Med 2008; 358:954-956.

3. Herrema H, Derks TG, van Dijk TH, Bloks VW, Gerding A, Havinga R, Tietge UJ, Muller M, Smit GP, Kuipers F et al: Disturbed hepatic carbohydrate management during high metabolic demand in medium-chain acyl-CoA dehydrogenase (MCAD)-deficient mice. Hepatology 2008; 47:1894-1904.

4. Almeida A, Cidad P, Bolanos JP: Nitric oxide accounts for an increased glycolytic rate in activated astrocytes through a glycogenolysis-independent mechanism. Brain Res 2002; 945:131-134.

5. Barke RA, Brady PS, Brady LJ: The Ca2+ second messenger system and interleukin-1-alpha modulation of hepatic gene transcription and mitochondrial fat oxidation. Surgery 1991; 110:285-294.

6. Nanni G, Siegel JH, Coleman B, Fader P, Castiglione R: Increased lipid fuel dependence in the critically ill septic patient. J Trauma 1984; 24:14-30.

7. Yamamoto T: Rat liver peroxisomal and mitochondrial fatty acid oxidation in sepsis. Surg Today 1993; 23:137-143.

8. Crouser ED, Julian MW, Huff JE, Joshi MS, Bauer JA, Gadd ME, Wewers MD, Pfeiffer DR: Abnormal permeability of inner and outer mitochondrial membranes contributes independently to mitochondrial dysfunction in the liver during acute endotoxemia. Crit Care Med 2004; 32:478-488.

9. Kantrow SP, Taylor DE, Carraway MS, Piantadosi CA: Oxidative metabolism in rat hepatocytes and mitochondria during sepsis. Arch Biochem Biophys 1997; 345:278-288.

10. Mela-Riker L, Bartos D, Vlessis AA, Widener L, Muller P, Trunkey DD: Chronic hyperdynamic sepsis in the rat. II. Characterization of liver and muscle energy metabolism. Circ Shock 1992; 36:83-92.

11. Harris HW, Gosnell JE, Kumwenda ZL: The lipemia of sepsis: triglyceride-rich lipoproteins as agents of innate immunity. $J$ Endotoxin Res 2000; 6:421-430.

12. Koskinas J, Gomatos IP, Tiniakos DG, Memos N, Boutsikou M, Garatzioti A, Archimandritis A, Betrosian A: Liver histology in ICU patients dying from sepsis: a clinico-pathological study. World J Gastroenterol 2008; 14:1389-1393.

13. Krinsley JS: The severity of sepsis: yet another factor influencing glycemic control. Crit Care 2008; 12:194.

14. Shcherbakova LN, Iakovleva, II, Molchanova LV: [Basic characteristics of lipid metabolism in patients with sepsis during kidney replacement therapy]. Anesteziol Reanimatol 2003:27-29.

15. Sim KG, Hammond J, Wilcken B: Strategies for the diagnosis of mitochondrial fatty acid beta-oxidation disorders. Clin Chim Acta 2002; 323:37-58.

16. Nishiyama A, Matsui M, Iwata S, Hirota K, Masutani H, Nakamura H, Takagi Y, 
Sono H, Gon Y, Yodoi J: Identification of thioredoxin-binding protein-2/vitamin $\mathrm{D}(3)$ up-regulated protein 1 as a negative regulator of thioredoxin function and expression. J Biol Chem 1999; 274:21645-21650.

17. Patwari P, Higgins LJ, Chutkow WA, Yoshioka J, Lee RT: The interaction of thioredoxin with Txnip. Evidence for formation of a mixed disulfide by disulfide exchange. J Biol Chem 2006; 281:21884-21891.

18. Junn E, Han SH, Im JY, Yang Y, Cho EW, Um HD, Kim DK, Lee KW, Han PL, Rhee SG et al: Vitamin D3 up-regulated protein 1 mediates oxidative stress via suppressing the thioredoxin function. J Immunol 2000; 164:6287-6295.

19. Ahsan MK, Masutani H, Yamaguchi Y, Kim YC, Nosaka K, Matsuoka M, Nishinaka Y, Maeda M, Yodoi J: Loss of interleukin-2-dependency in HTLV-I-infected $\mathrm{T}$ cells on gene silencing of thioredoxin-binding protein-2. Oncogene 2006; 25:2181-2191.

20. Oka S, Liu W, Masutani H, Hirata H, Shinkai Y, Yamada S, Yoshida T, Nakamura H, Yodoi J: Impaired fatty acid utilization in thioredoxin binding protein-2 (TBP-2)-deficient mice: a unique animal model of Reye syndrome. Faseb J 2006; 20:121-123.

21. Okuyama H, Yoshida T, Son A, Oka S, Wang D, Nakayama R, Masutani H, Nakamura H, Nabeshima Y, Yodoi J: Thioredoxin binding protein 2 modulates natural killer $\mathrm{T}$ cell-dependent innate immunity in the liver: possible link to lipid metabolism. Antioxid Redox Signal 2009; 11:2585-2593.

22. Bodnar JS, Chatterjee A, Castellani LW, Ross DA, Ohmen J, Cavalcoli J, Wu C, Dains KM, Catanese J, Chu $\mathrm{M}$ et al: Positional cloning of the combined hyperlipidemia gene Hyplip1. Nat Genet 2002; 30:110-116.

23. Oka S, Yoshihara E, Bizen-Abe A, Liu W, Watanabe M, Yodoi J, Masutani H: Thioredoxin binding protein-2/thioredoxin-interacting protein is a critical regulator of insulin secretion and peroxisome proliferator-activated receptor function. Endocrinology 2009; 150:1225-1234.

24. Puigserver P, Rhee J, Donovan J, Walkey CJ, Yoon JC, Oriente F, Kitamura Y, Altomonte J, Dong H, Accili D et al: Insulin-regulated hepatic gluconeogenesis through FOXO1-PGC-1alpha interaction. Nature 2003; 423:550-555.

25. Saudubray JM, Martin D, de Lonlay P, Touati G, Poggi-Travert F, Bonnet D, Jouvet $\mathrm{P}$, Boutron M, Slama A, Vianey-Saban $\mathrm{C}$ et al: Recognition and management of fatty acid oxidation defects: a series of 107 patients. J Inherit Metab Dis 1999; 22:488-502.

26. Vriesendorp TM, DeVries JH, Hoekstra JB: Hypoglycemia and strict glycemic control in critically ill patients. Curr Opin Crit Care 2008; 14:397-402.

27. Fredriksson K, Tjader I, Keller P, Petrovic N, Ahlman B, Scheele C, Wernerman J, Timmons JA, Rooyackers O: Dysregulation of mitochondrial dynamics and the muscle transcriptome in ICU patients suffering from sepsis induced multiple organ failure. PLoS ONE 2008; 3:e3686.

28. Hui TY, Sheth SS, Diffley JM, Potter DW, Lusis AJ, Attie AD, Davis RA: Mice lacking thioredoxin-interacting protein provide evidence linking cellular redox state to appropriate response to nutritional signals. J Biol Chem 2004; 279:24387-24393. 
29. Alamdari N, Constantin-Teodosiu D, Murton AJ, Gardiner SM, Bennett T, Layfield R, Greenhaff PL: Temporal changes in the involvement of pyruvate dehydrogenase complex in muscle lactate accumulation during lipopolysaccharide infusion in rats. J Physiol 2008; 586:1767-1775. 
A

Males

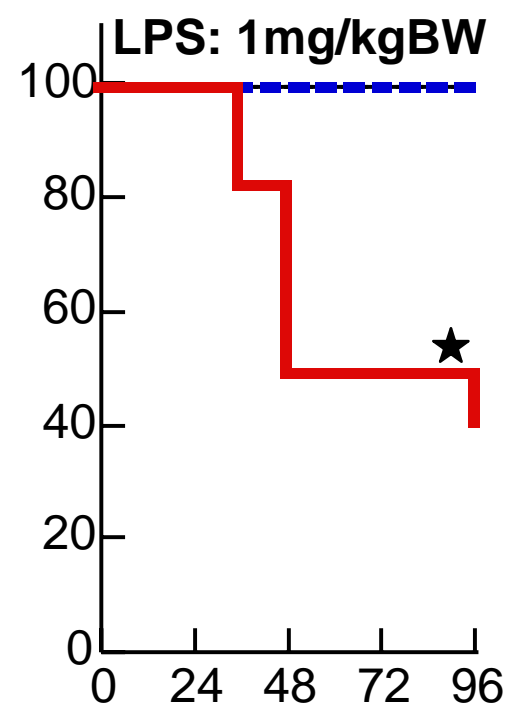

Females

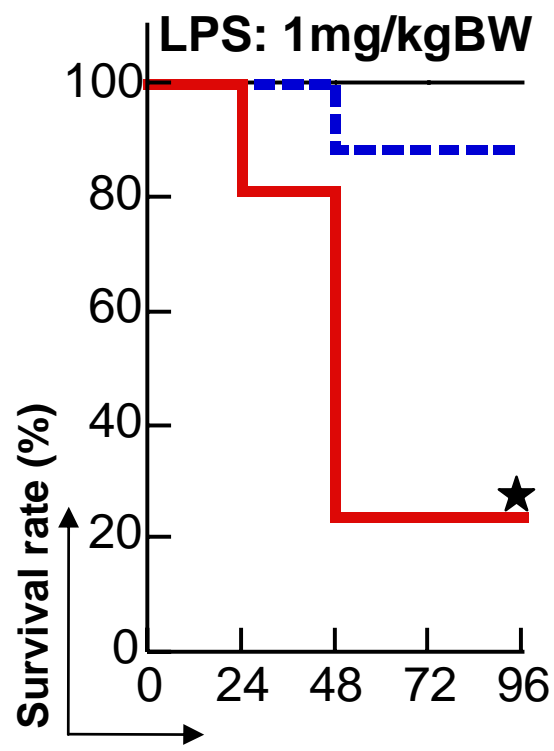

Time (hours)

B

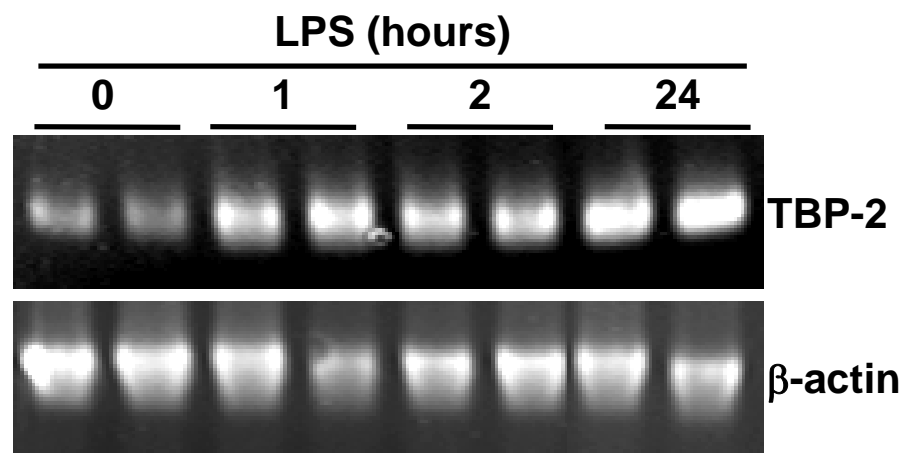

Fig. 1
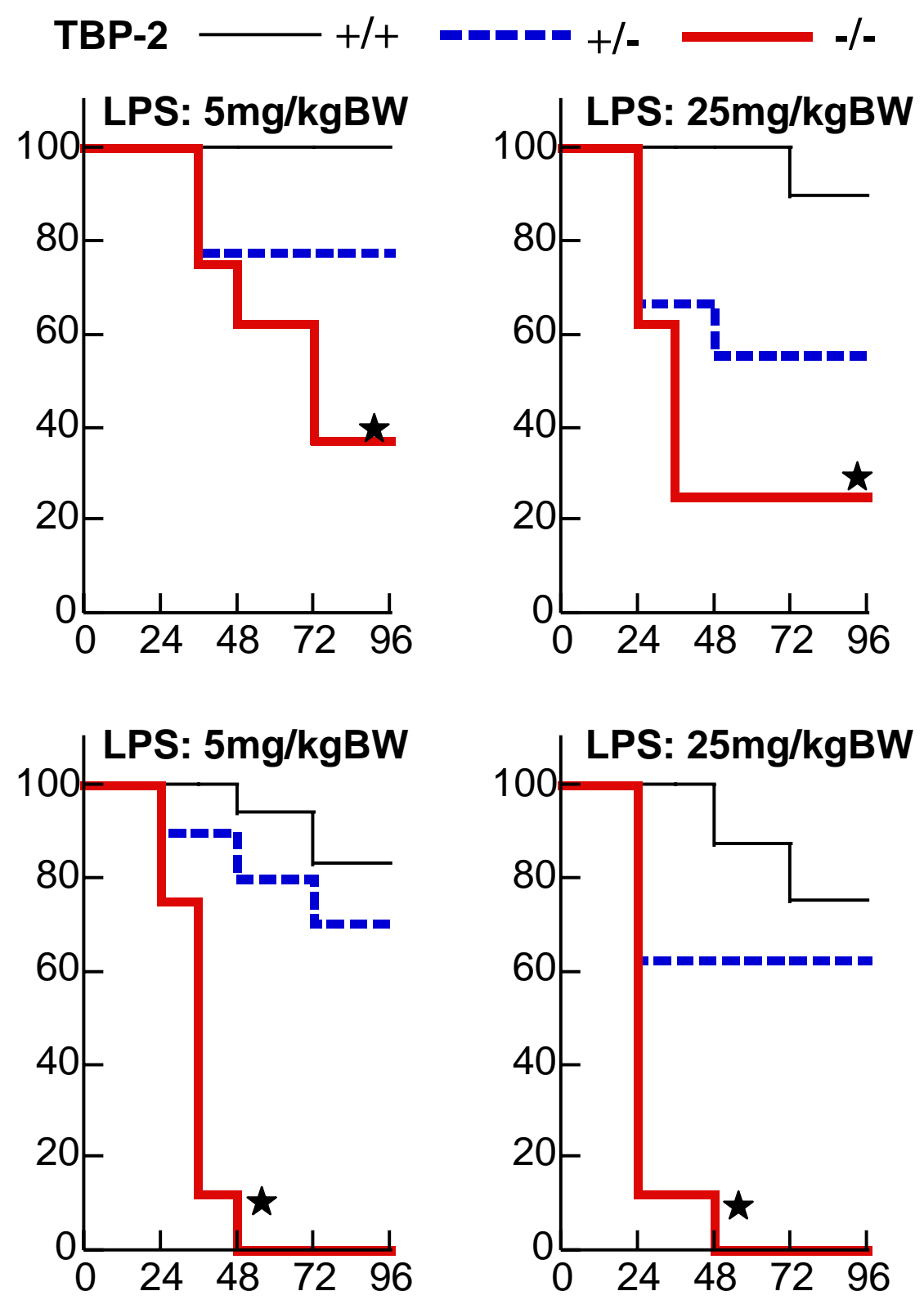

C

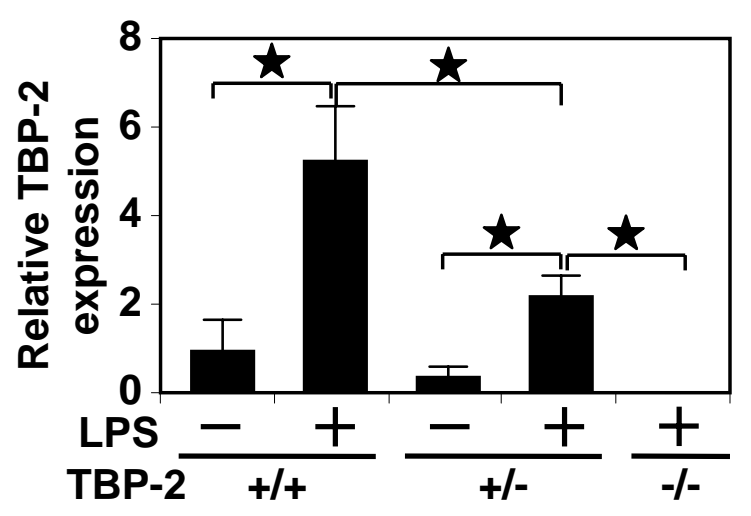


A

Fig. 2
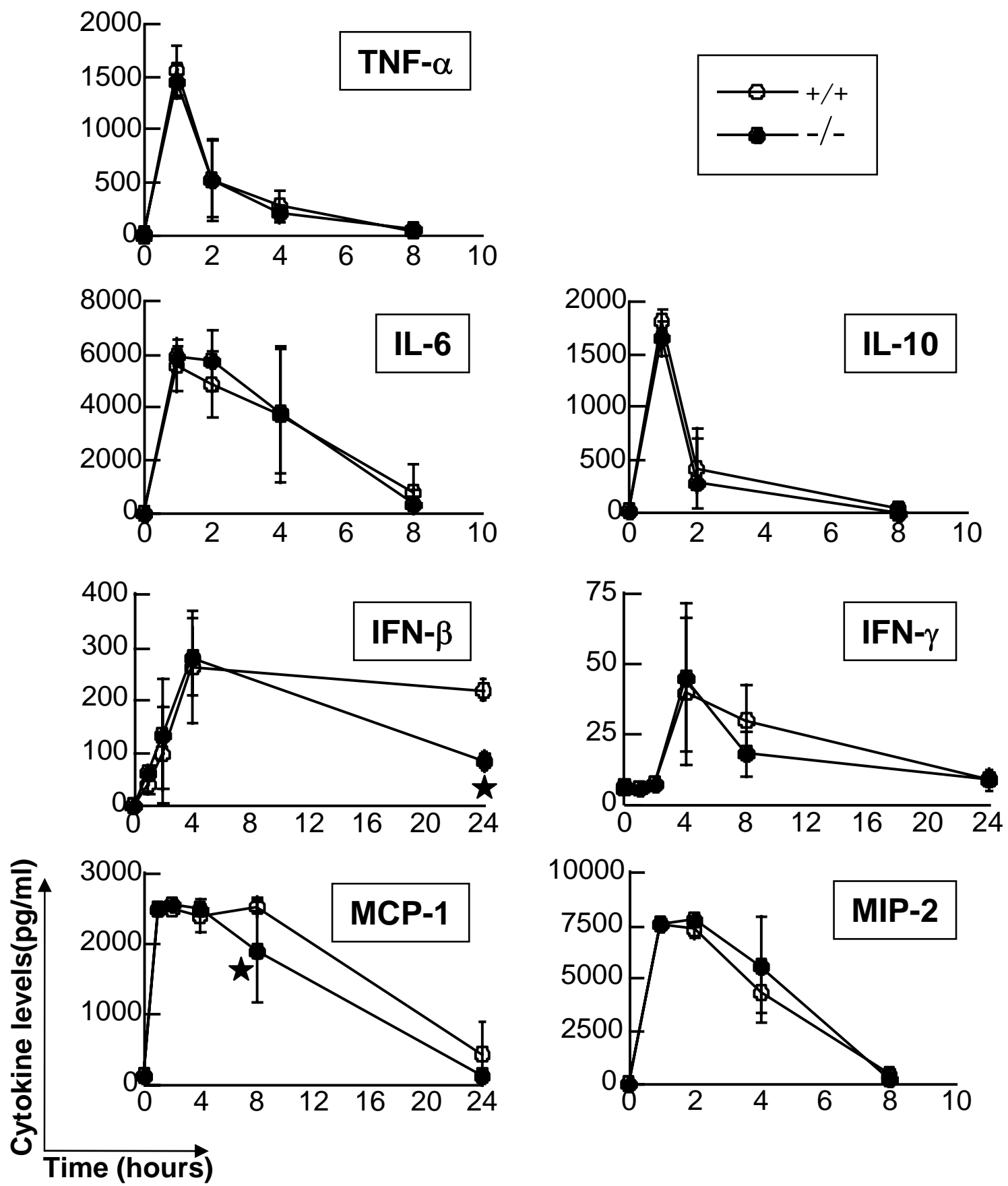

B

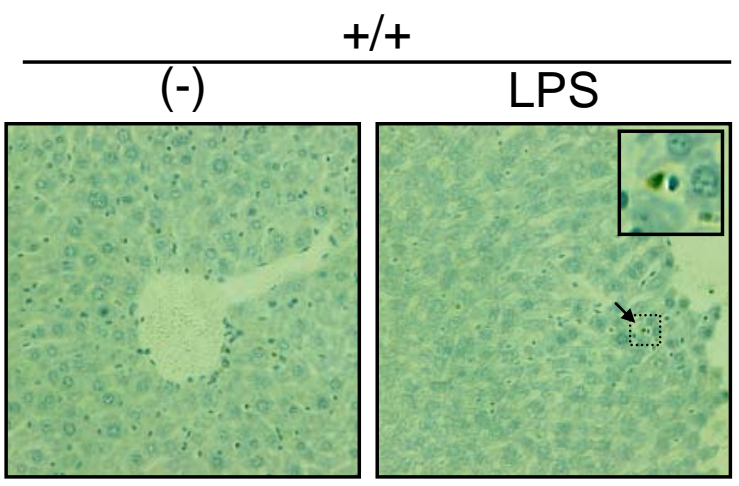

$-1-$

$(-) \quad$ LPS

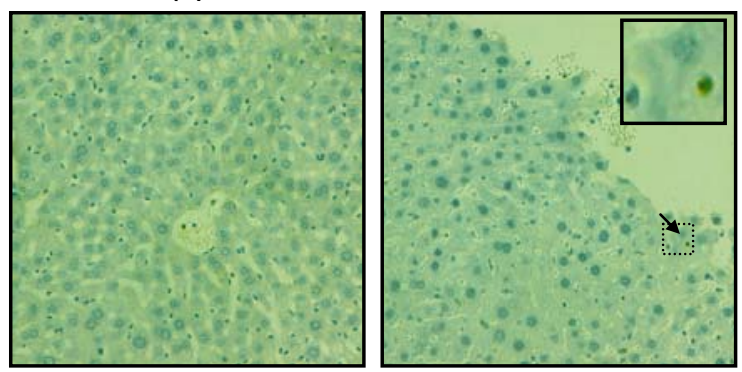


Fig. 3

A
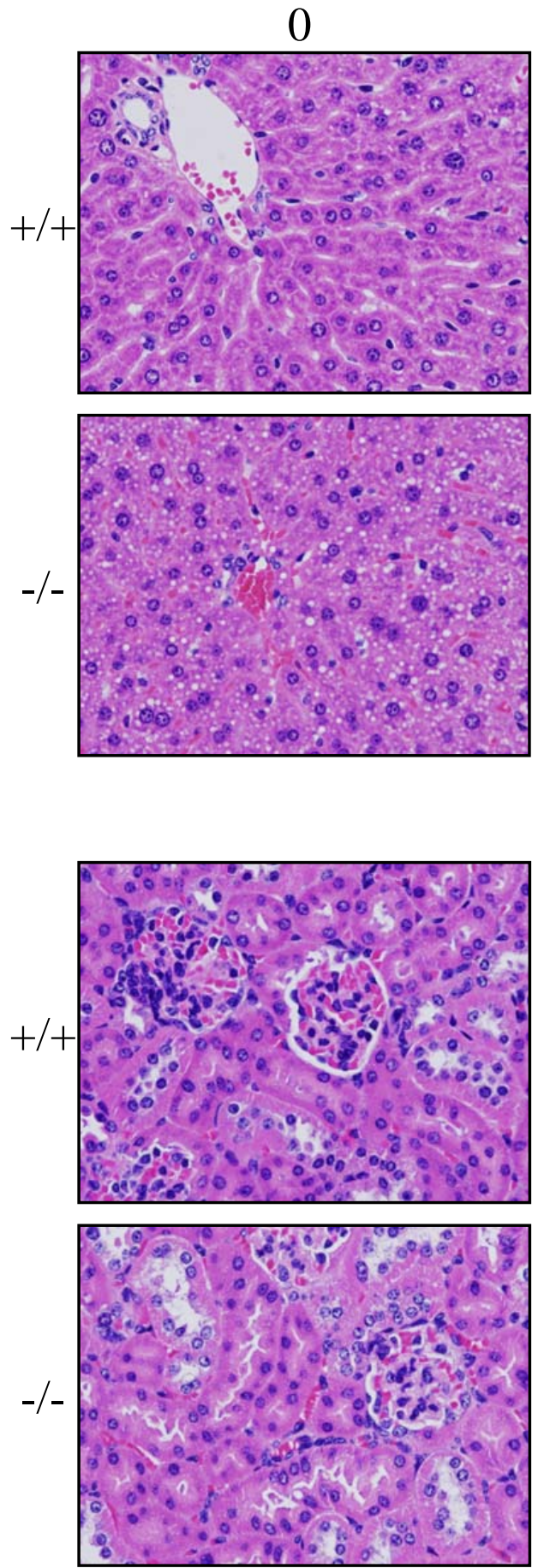

LPS (hours)
24
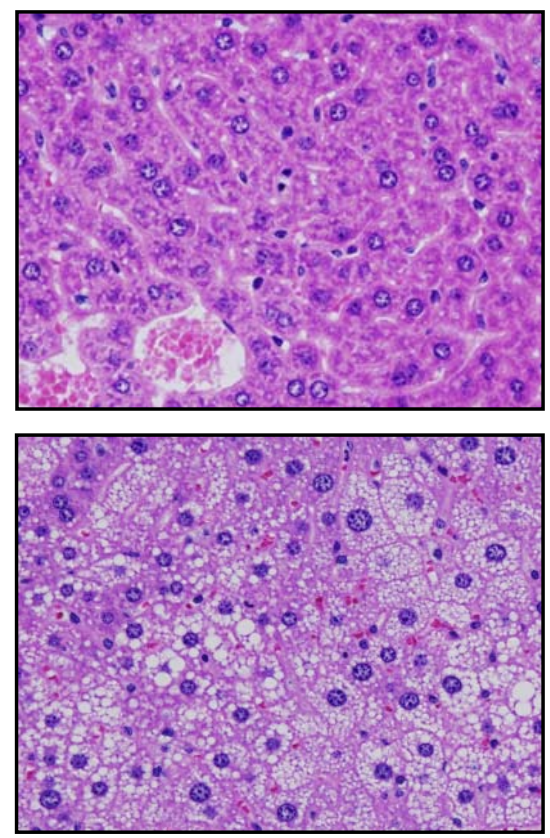

44
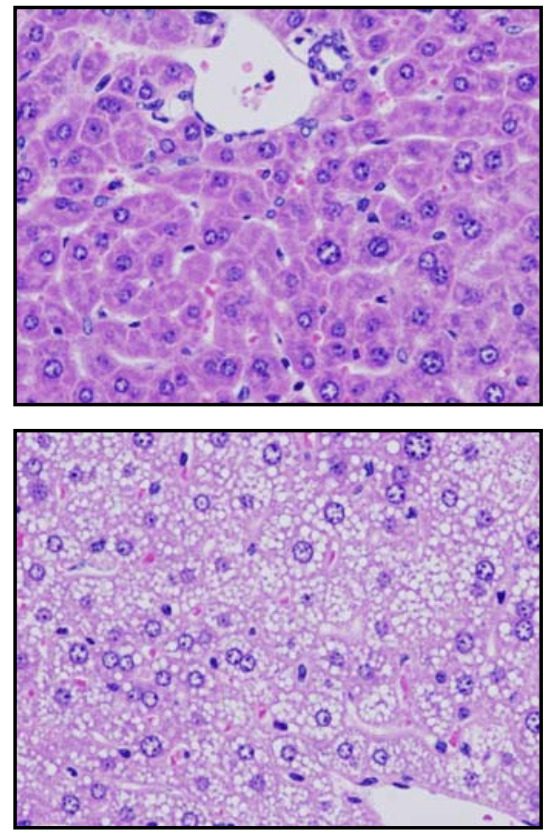

Liver
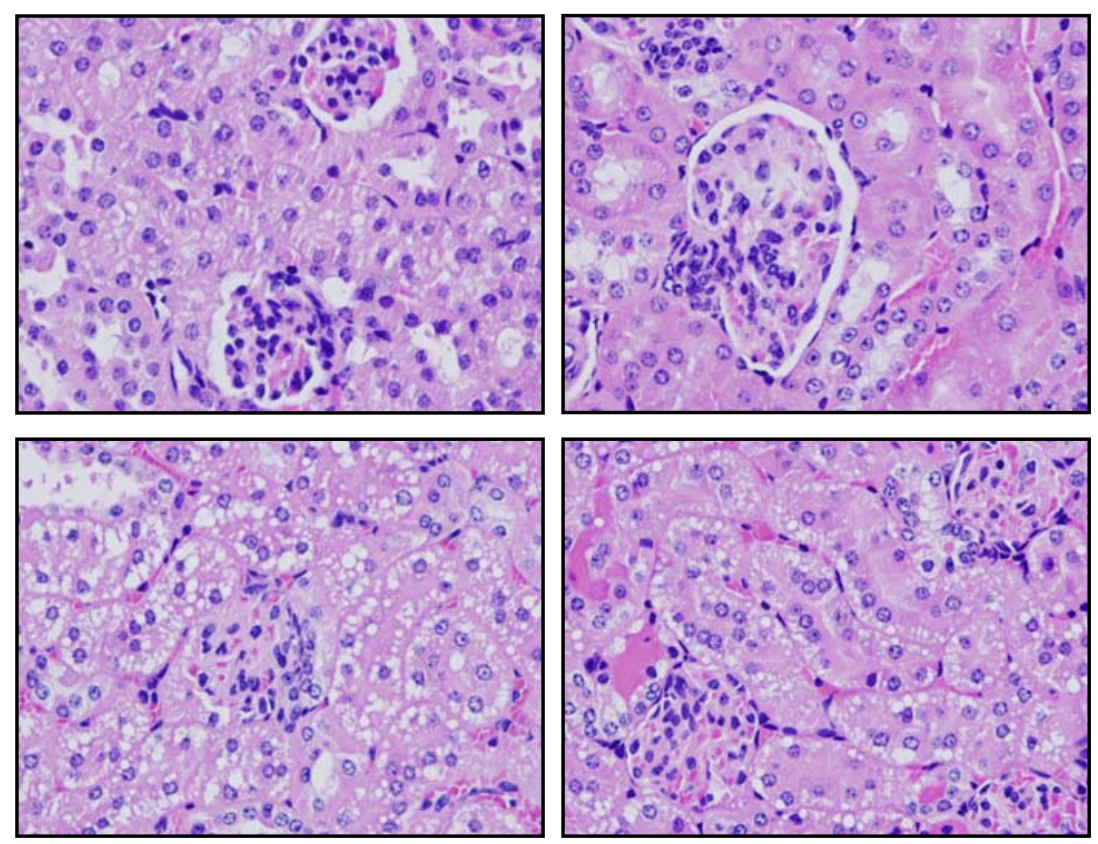

Kidney 
Fig. 3

B
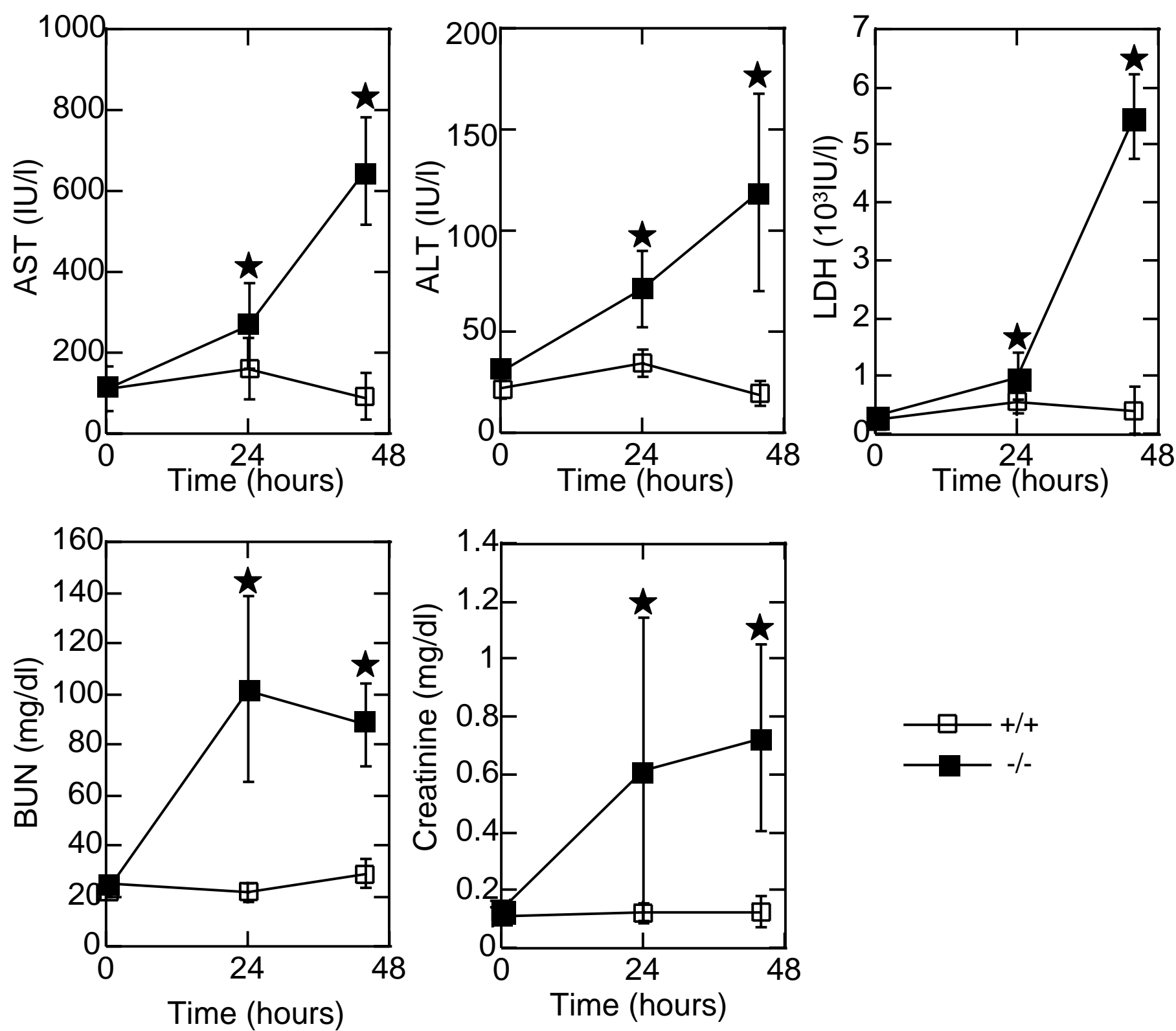
Fig. 4

A
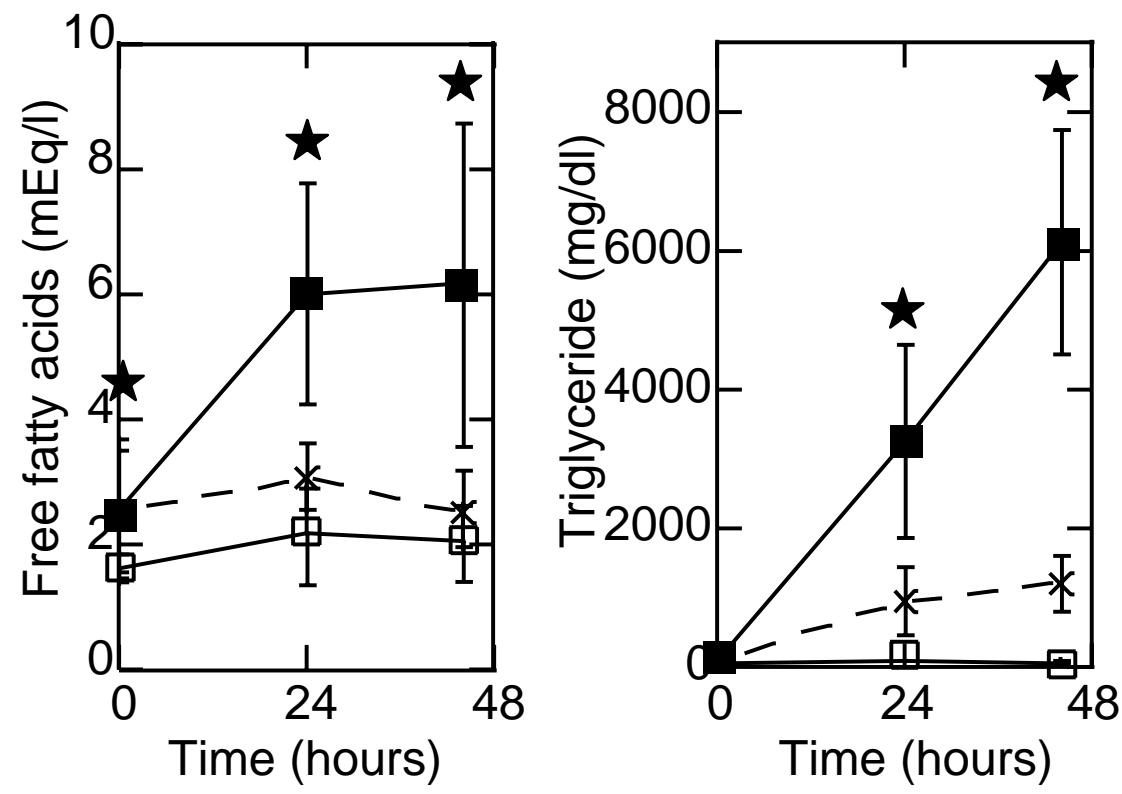

LPS $\left\{\begin{array}{l}\frac{\square}{-1+}-1- \\ -\frac{-1}{-}\end{array}\right.$

Fasting $-x-\quad-/-$
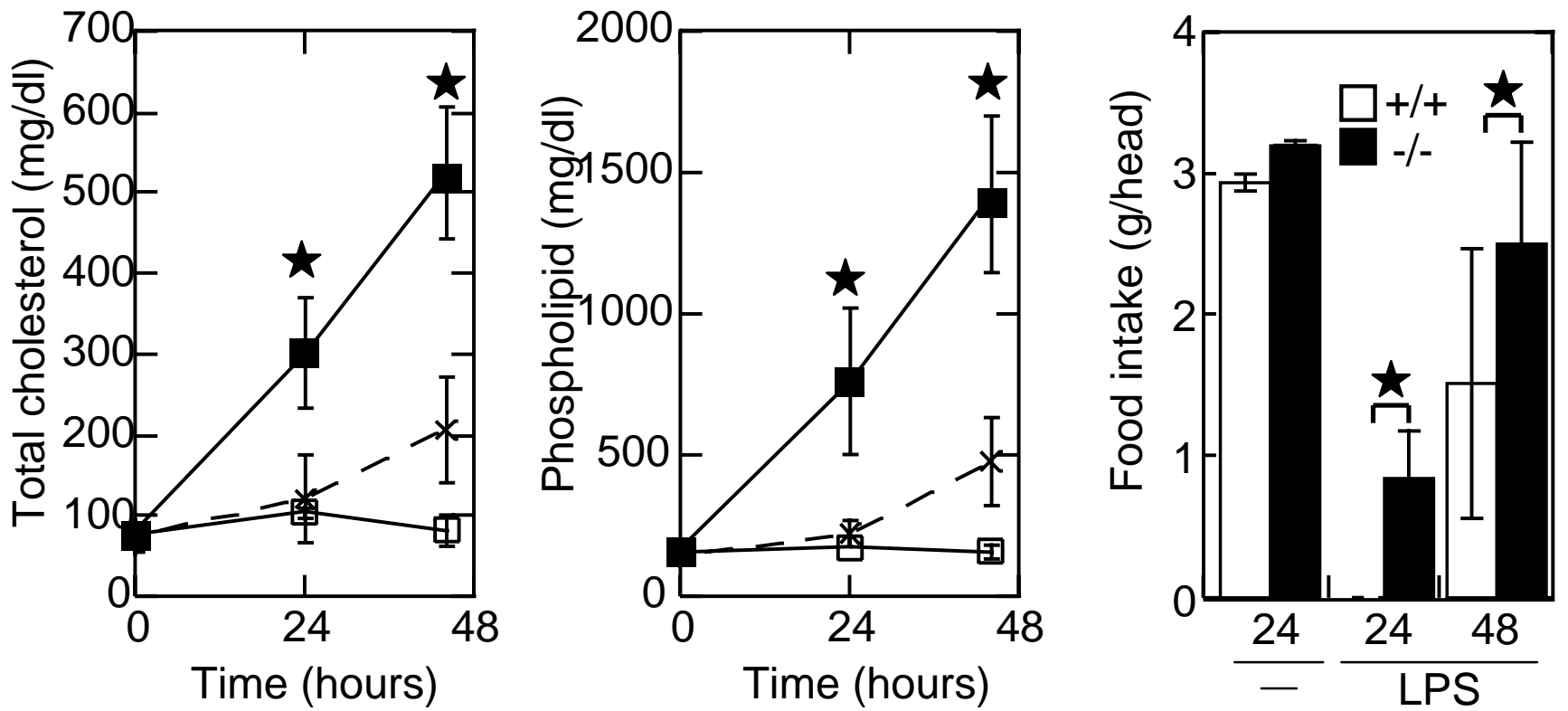
Fig. 5

A

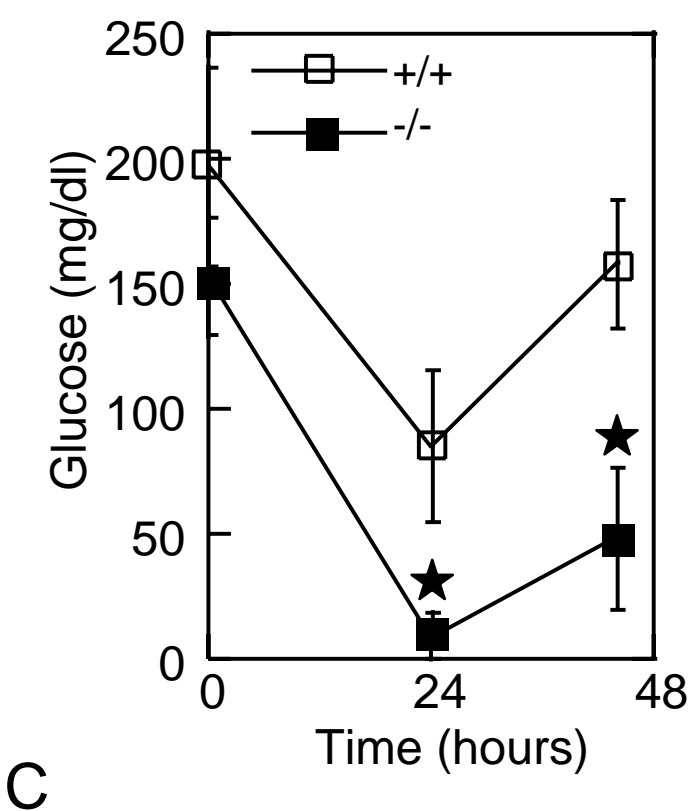

$(-)$

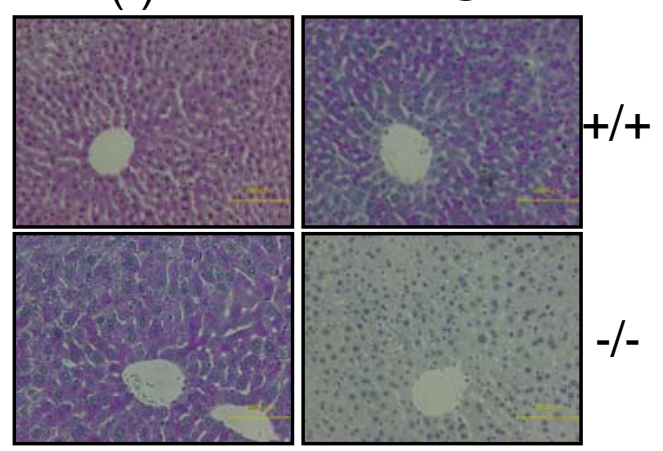

B
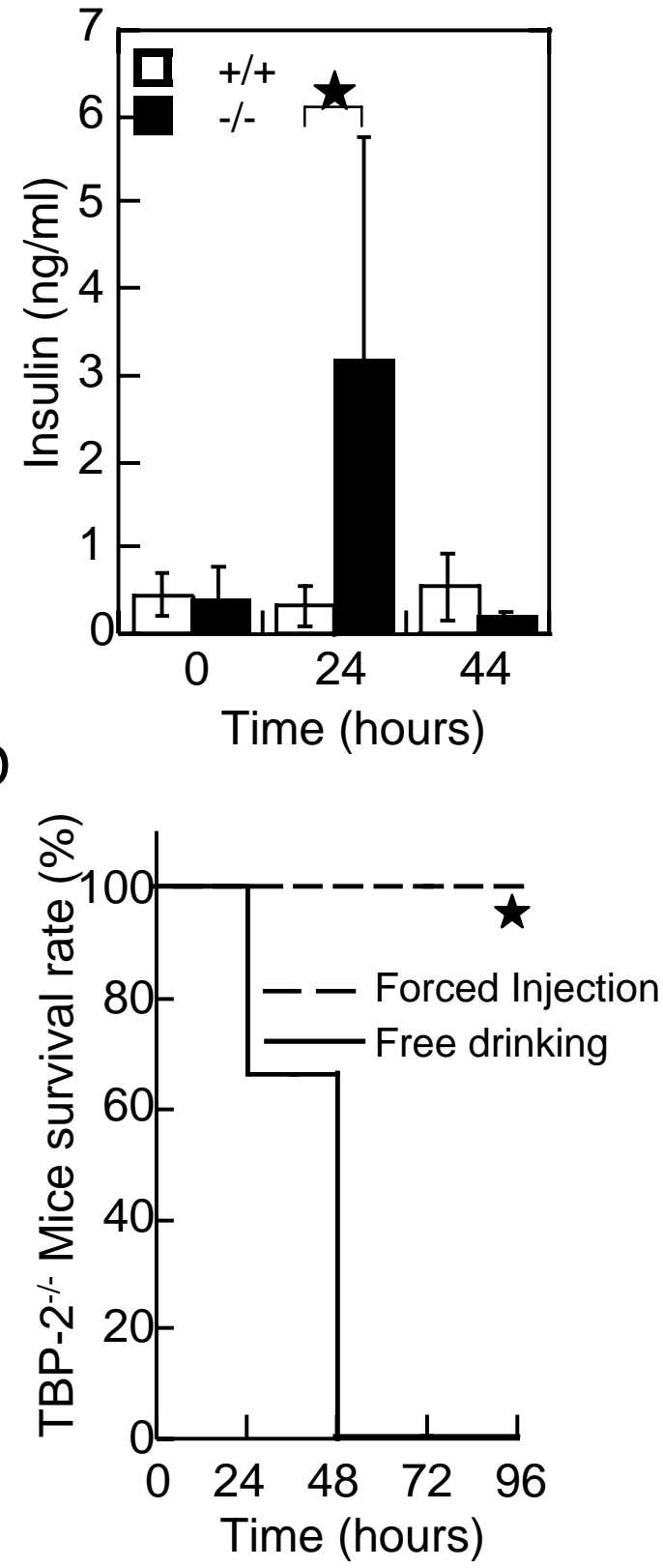
Fig. 6
A
B
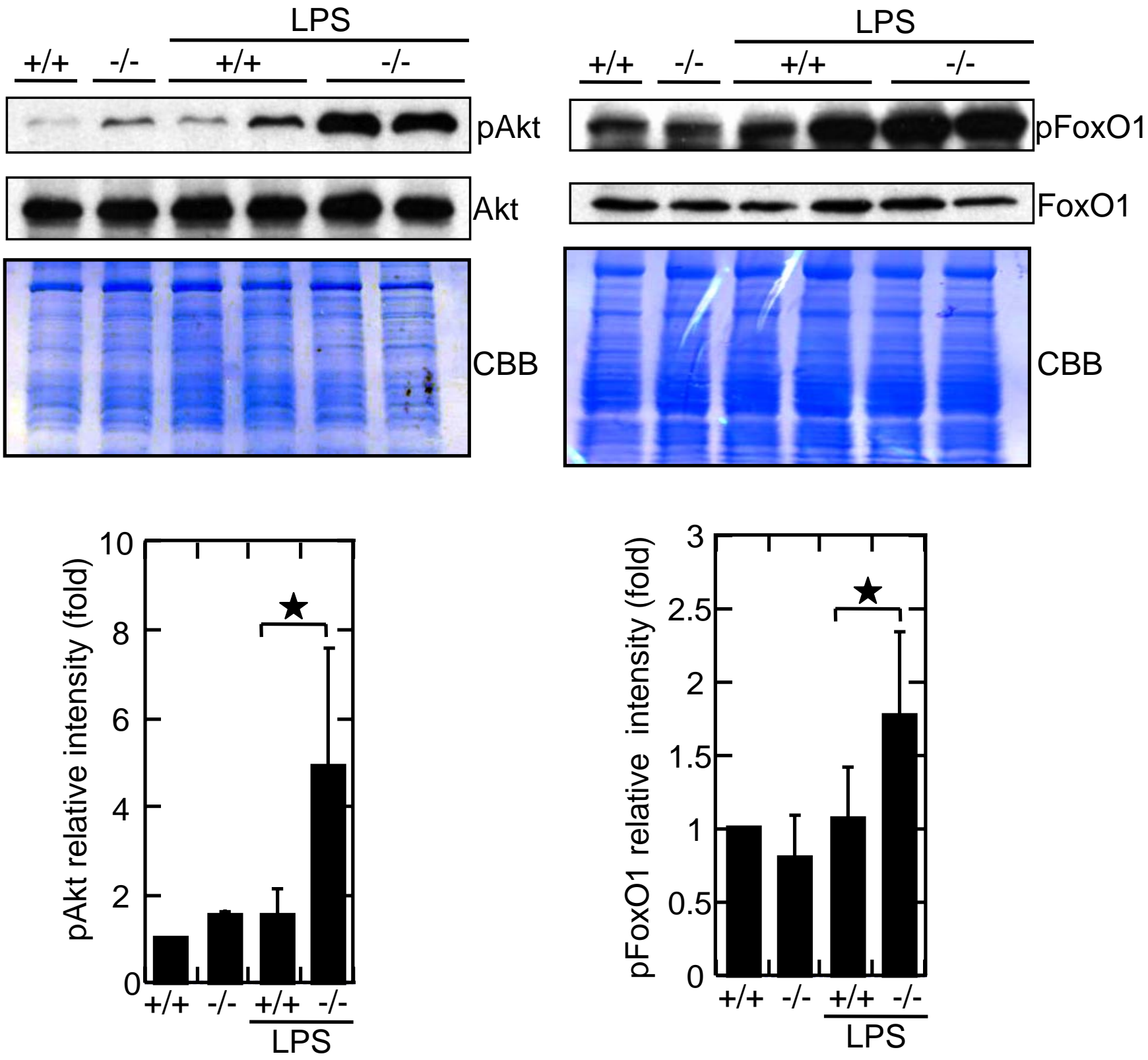
Supplementary Fig. 1

A
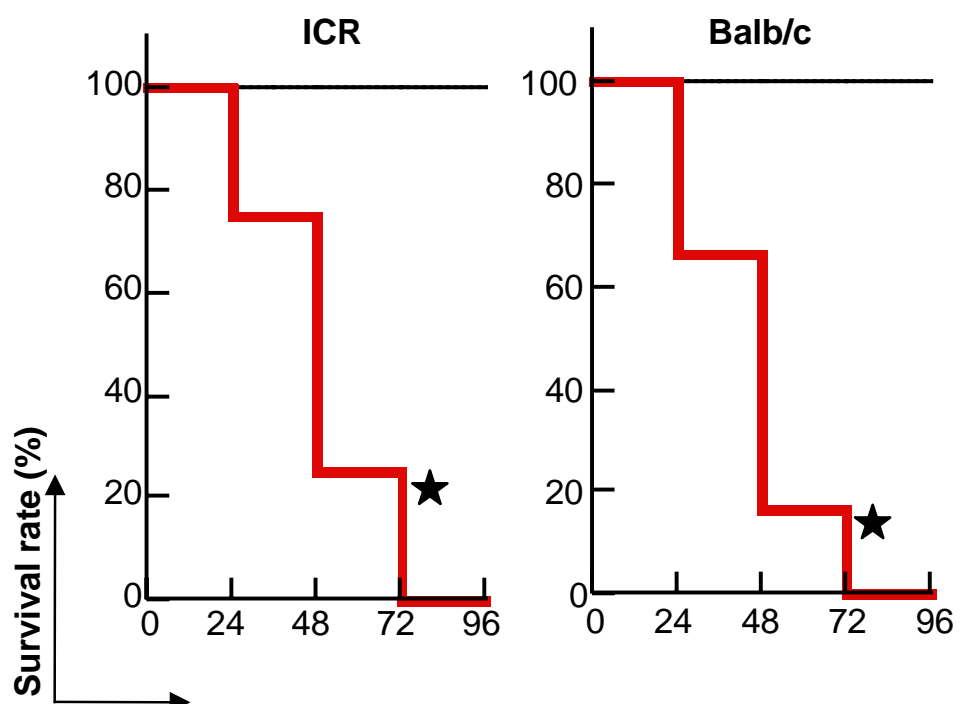

Time (hours)

B
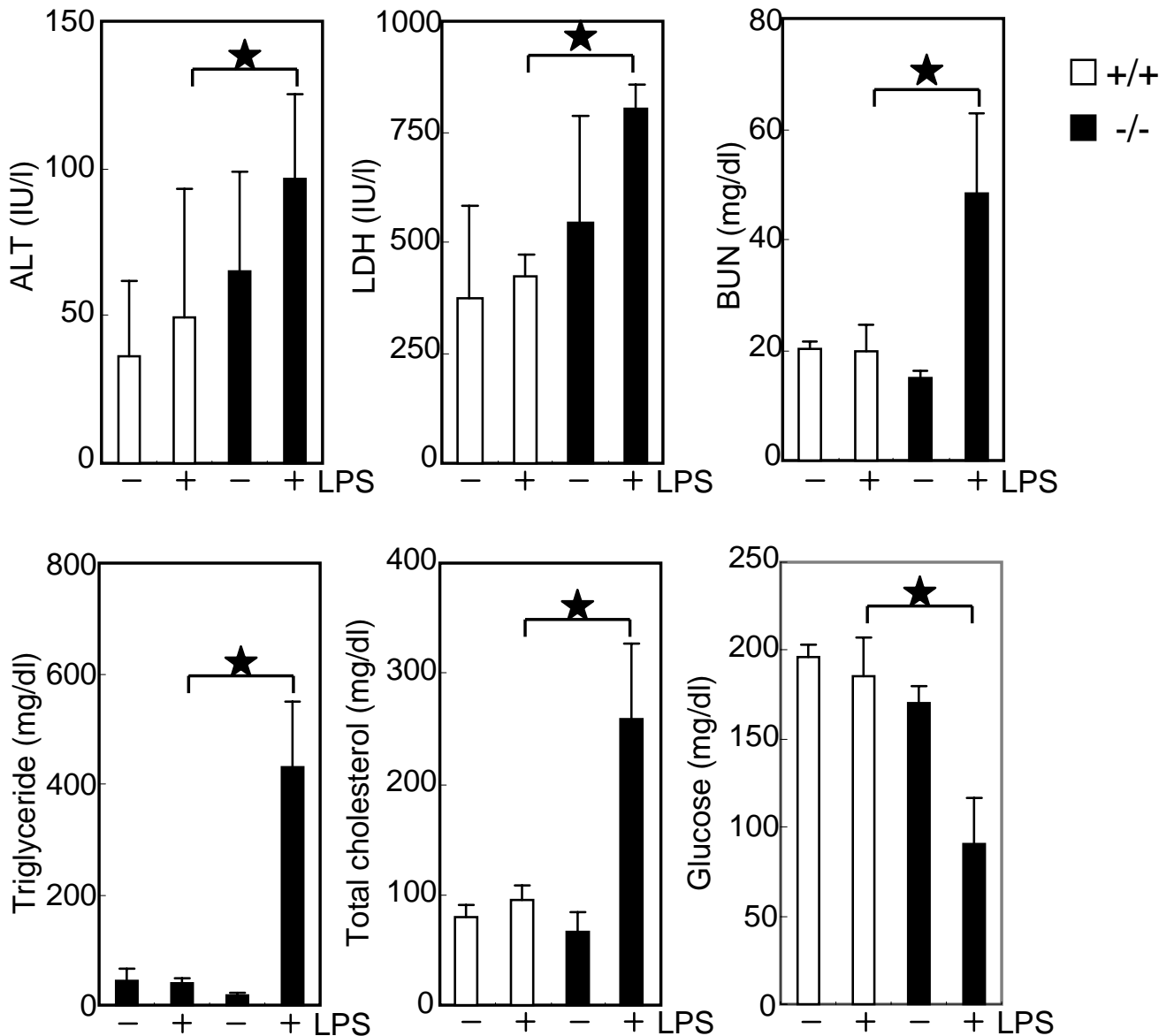


\section{Supplementary Fig. 2}

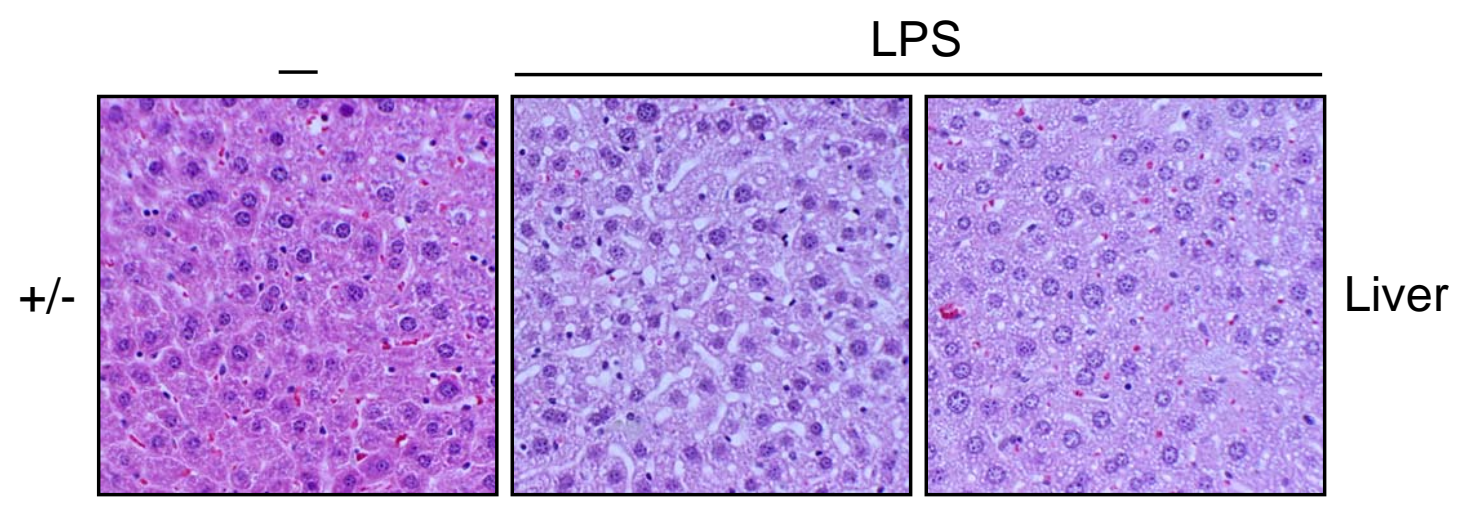

\section{Supplementary Fig. 3}

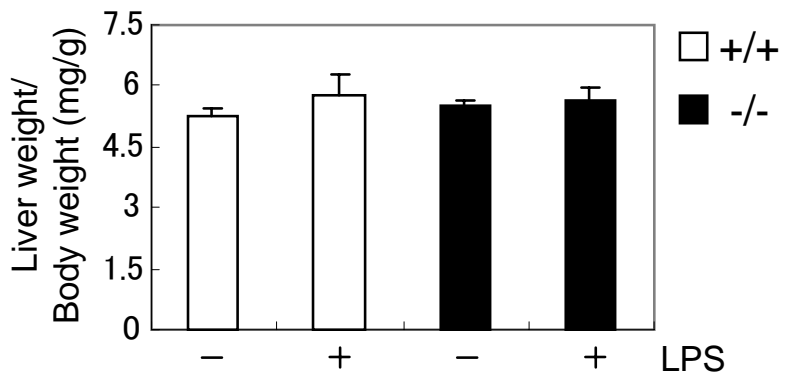

Supplementary Fig. 4

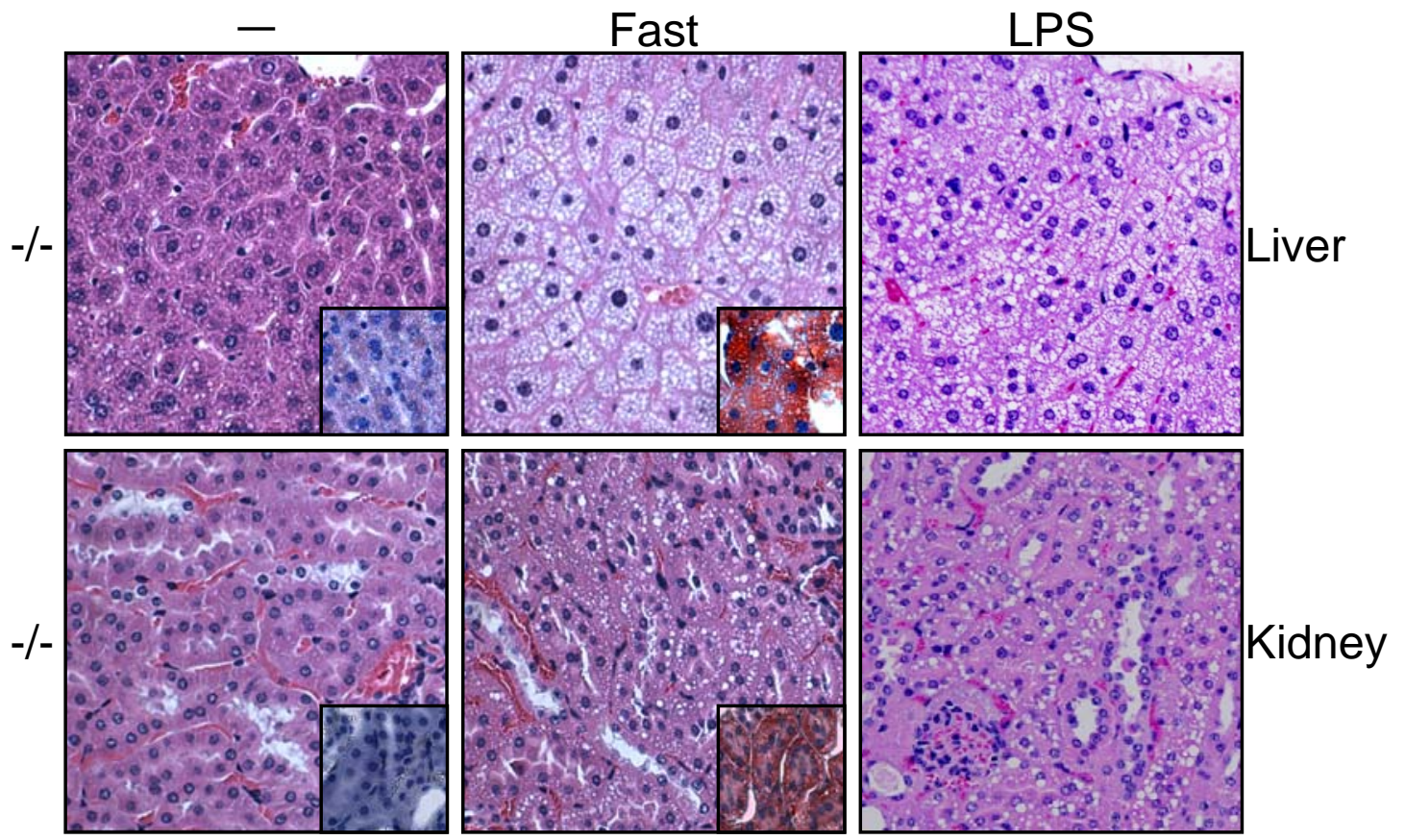

